\title{
No Extreme any More, Strike a Balance
}

\author{
Negah Allahyar \\ Universiti Sains Malaysia, Malaysia \\ E-mail: negah_al@hotmail.com \\ Shiva Ramezanpour \\ Universiti Sains Malaysia, Malaysia \\ E-mail: shivaramezanpour@.gmail.com
}

Received: August 21, $2010 \quad$ Accepted: December 3, 2010 doi:10.5539/ass.v7n5p240

\begin{abstract}
During the last few years, different ways of approaching grammar have been the subject of much debate. Unlike Numerous studies have explored the advantages and disadvantages of such approaches, little discussion exists on the actual process of grammar instruction and instances of grammar presentation. This article is an attempt to address the state of grammar in Iranian public schools and private language centres, uncover the main reasons why deductive and inductive grammar have been bound to fail, Then it calls for a critical review of grammar in Education system as a key feature of the language curriculum and comes up with some suggestions. The purpose of this paper is giving a clear picture to those researchers who are interested to work in the area of grammar. For those education centres which want to reflect on realistic situation and improve their curricula and teacher training programs.
\end{abstract}

Keywords: Deductive grammar, Inductive grammar, GBT

\section{Introduction}

Lack of teaching grammar is a hot issue among language professionals and practitioners. Whereas the effect of grammar on acquisition is still controversial, most teachers lay great stress on its necessity. During the past few years, different approaches to grammar have been developed, however, Inductive and deductive approaches have been umbrella terms covering all.

\section{Deductive, inductive or a third alternative (combination of both)}

Grammar is traditionally taught deductively. A deductive approach starts with moving from general to specific and gives a presentation of a rule which is followed by example drills.

Another alternative is inductive grammar teaching in which learners are given many examples in different contexts and they are asked to work out the rules by themselves, and then apply them to various exercises to learn how they actually work in real language use.

A lot of research has compared these two approaches, No big differences have been reported in favor of either though (Erlam, 2003).

\section{Advantages of the deductive approach to grammar presentation}

1). It is time-saving.

2). Rules are simply and clearly explained

3). Immediate application of the rules through direct examples is provided.

4). It respects the intelligence and maturity of the adult learners

5). It meets the expectations of those learners who have analytical style (Widodo, 2006).

\section{Advantages of the inductive approach to grammar presentation}

1). Rule discovery can lead to learning autonomy and self-reliance.

2)." Learners' greater degree of cognitive depth is exploited". 
3). It is learner centered; Learners are more active and motivated.

4). It motivates the learners seek challenges through "pattern-recognition and problem solving"(Widodo, 2006, p. 127).

\section{Third alternative}

A third alternative to grammar teaching is intermingling both inductive and deductive approaches and benefiting from the advantages of both.

\subsection{GBT a third alternative (combination of both)}

Grammar based teaching (GBT) is an approach recommended by Azar to grammar practitioners believes that "placing specific grammar structures within their larger conceptual framework is more helpful to students than a random, piecemeal approach to explicit grammar teaching" (Azar, 2007). GBT is a way of incorporating CLT into a structural syllabus and showing "how English works" (p.4). It takes advantages of inductive and deductive and uses grammar as a "springboard for interactive, communicative practice opportunities" (Azar, 2007, p.7).

\section{Which one to choose?}

As Prince \& Felder ( 2006) point out "Like the scientific method, learning invariably involves movement in both directions, with the student using new observations to infer rules and theories (induction) and then testing the theories by using them to deduce consequences and applications that can be verified experimentally (deduction)" (p.3).

Incongruities found between teachers' beliefs and practices regarding grammar instructions (Borg, 2001; Allahyar, 2006) indicate that grammar is no exception, in other words, in practice, teaching and learning grammar cannot be purely inductive or deductive. Unlike Numerous studies have explored the advantages and disadvantages of inductive or deductive approaches, little discussion exists on the actual process of grammar instruction and instances of grammar presentation.

A brief look at the literature on the actual process of grammar instruction reflects the teachers' decisions about grammar has been greatly influenced by conflicting cognitions about language, learning, grammar teaching, and students or teachers' knowledge of and about grammar (KAL,KAG) (Borg,1999, 2001). No research has investigated how incomplete and imprecise notions of inductive or deductive grammar approach or unsuccessful adoption of each might lead to its complete failure. In other words as Prince et al (2006) argue it is not easy to say that simply adopting an inductive method will automatically lead to better learning and more satisfied students as with any form of instruction, inductive teaching can be done well or poorly"(p. 23).

\section{An overview of grammar teaching in Iran}

Grammar Translation Method (GTM) has been practiced in public classes for many years. Like all traditional classes, Persian (L1) is used for translation of the written texts and grammar teaching.The students are never required to translate sentences from their mother tongue into English. Deductive grammar approach is a guarantee for students' success in their achievement tests or their university entrance examination. Learners are given the grammar rules and are asked to then apply the rules to other examples; the teachers who explain grammar well are really welcomed and complimented.

The deficiency of schools and universities in producing communicative language learners has led to the growth of more private language centers (Talebinezhad \& Sadeghi, 2005) which give an undivided attention to communication rather than grammar to meet students' needs and grab more customers.

\subsection{Grammar in private language centers}

Language centres have just realized that students have been deeply frustrated by grammar in general because they have gone over the rules umpteen times, yet they can not apply them to communicative tasks. In most private language centres, presenting grammar deductively and L1 use are totally banned. Syllabi are based on themes instead of grammar points and that teachers spend less time on grammar drills and more time on discussions and communicative activities. Teachers are told to approach grammar inductively or explore it rarely and motivate their students to speak even if they do not know a word.

They are also asked to treat errors cautiously so as not to blunt students' motivation or destroy their confidence.

The questions are

- Why grammar is seldom grasped though it is taught very much? 
- Why High school teachers spend a lot of time teaching the grammatical terms and rules to prepare their students for their achievement and university competitive tests but students have no solid grammatical foundation?

- Why student make so many simple grammatical errors while they have been overexposed to grammar for many years?

What is wrong?

\section{Misconception about inductive and deductive grammar teaching}

For many years the adoption of communicative language teaching and English -only policy at private language centres in Iran have had a dominant influence on the ways in which teachers see and interpret grammar. However, our knowledge about teachers' perception of teaching grammar in Iranian language institutes is limited.

Nonetheless, Allahyar's qualitative study (2004) on teacher perspective on grammar teaching shows that teachers use deductive approach and GTM interchangeably, to them, the practice of deductive approach necessarily means using L1 as the medium of instruction or it necessarily means following the principles of GTM and when it is spoken of inductive grammar instruction, they think of presenting grammar through ample of examples without remembering the fact that the students are required to infer the rules from contextualized practice, or go through the process of "Discovery learning" (Ellis, 2002).

Moreover, the teachers attribute students' deficiency in communication to "deductive approach" the term by which they mean GTM. Though presenting grammar deductively and L1 use are totally banned in private language centres, observations show that most of the classes have "the features of traditional and communicative classes". Most lessons are teacher-fronted with an explicit 'focus on form'. Grammar activities are traditional than communicative type (Allahyar, 2006).Teachers do not give the students an opportunity to make sense of grammar through examples and provide them with the rules than eliciting the rules from the students themselves.

In the light of the above, it is clear that the lack of understanding of GTM, CLT and English only policy have made the teachers to stick to two opposite extremes. At one extreme, they doubt the value and place of grammar, at the other extreme, they present grammar deductively just in medium of L2, though they think they are practicing it inductively.

Those who are falling in the first category, laying too much emphasis on fluency and speaking skills and this leads to producing lots of students without a good knowledge of grammar and those who are in the second category including public language teachers, deprive the students of having the opportunity to practice those grammatical points which means they are depriving them of the essence of learning it.

Looking back at the previous research, it is assumed that the high school students' inability in communication mainly derives from the lack of the exposure to L2 or rare practice of translating sentences from L1 into L2. It is naive to assume that it is because of adoption of the deductive grammar instruction. However, a lack of study in this area suggests the need for considerably more investigation.

Undoubtedly, if the teachers do not appreciate the differences between two approaches or if they do not raise their awareness of their classes, they might incite their students' hatred against grammar unconsciously.

\section{Conclusion, Pedagogical implications for EFL teachers and suggestions}

Teaching and learning grammar cannot be purely inductive or deductive because learning by its nature involves movement in both directions as Prince et al. (2006) argue, though the deductive approach is very dominant in the EFL educational system. Intermingling both deductive and inductive approaches can be very effective. Beyond the shadow of doubt, unsuccessful learning is not a matter of using one approach instead of another.

It is a pressing matter of incomplete and imprecise notions of each approach or its unsuccessful adoption.

This paper calls for a critical review of grammar in Education system and attempts at giving a clear picture to those education centres which want to reflect on realistic situation and improve their curricula and teacher training programs.

It is also an imperative demand on language teachers to take care of the following suggestions.

\subsection{Arouse students' interest in grammar self study}

Look at grammar as a tool which develop your students' grammatical competence, and gives them "an ability to interpret the complex nuances of meaning within a text" (Kolln \& Hancock, 2005). 
Break down misconceptions of grammar and arouse students' interest in grammar self study by introducing different websites and books.

\subsection{Heightened expectations for accuracy leads to frustration, Be more patient}

Gauge how far from your expectations students' abilities stand. Unrealistic expectations from students make both teachers and students get frustrated. Think of factors such as the students' age, proficiency level, and educational background while teaching grammar (Celce-Murcia, 1991).

\subsection{Never mislead your learners at any cost. Make a professional grammarian out of you}

For more teachers making a good impression is of a greater importance than making a more efficient conveyance even at the cost of misleading the learners or neglecting their needs (Allayar, 2006). Language teacher are required to learn more about the language, and their knowledge should be about and of grammar whether they use deductive or inductive approach

9.4 Avoid any extreme, be free from any bias and enjoy alternative teaching approaches

The rationale used to justify inductive approach in the classroom is not conclusive. Be free from any bias and use different approaches. GBT can be of much help to develop fluency and accuracy of your students.

\section{References}

Allahyar, N. (2004). Teachers' perspective on Grammar teaching. Unpublished Master's Thesis, Islamic Azad UniversityGarmsar, Iran.

Allahyar, N. (2006). Teachers' perspective on Grammar teaching. The Science and Art of Language in Teaching (SALT) International Conference -Change: Bridging Theory and Practice. Malaysia.

Azar, B. (2007). Grammar-based teaching: A practitioner's perspective. TESL-EJ, 11(2), 1-12.

Borg, S. (1999). The use of grammatical terminological in the second language classroom: A qualitative study of teachers' practices and cognition. Applied linguistics, 20(1), 95-126.

Borg, S. (2001). Self perception and practice in teaching grammar. ELT journal, 55, 21-29.

Celce-Murcia, M. (1991). Grammar pedagogy in second and foreign Language teaching. TESOL Quarterly, 25, 459-480.

Ellis, R. (2002). Grammar teaching-practice or consciousness-raising? Methodology in language teaching: An anthology of current practice. (J. Richards \& W. W. Renandya) (pp. 167-174). Cambridge: Cambridge University Press.

Erlam, R. (2003). The Effects of Deductive and Inductive Instruction on the Acquisition of Direct Object Pronouns in French as a Second Language. The Modern Language Journal, 87(2), 242-260.

Kolln, M., \& Hancock, C. (2005). The story of English grammar in United States schools. English Teaching. Practice and Critique, 4(3), 11-31. [Online] Available: http://education.waikato.ac.nz/research/files/etpc/2005v4n3art1.pdf .

Prince., M., \& Felder, R. (2006). Inductive Teaching and Learning Methods: Definitions, Comparisons, and Research Bases. J. Eng. Education, 95(2), 123-138.

Talebinezhad, M. R., \& Sadeghi, A. (2005). Non-academic L2 users: A neglected research pool in ELT in Iran. Linguistik online, 24(4). [Online] Available: http://www.linguistikonline.de/27_07/talebinezhadaliakbari.html (March 18, 2008).

Widodo, H. (2006). Approaches and procedures for teaching grammar, English Teaching. Practice and Critique, 5(1), 27-38. [Online] Available: http://www.education.waikato.ac.nz/research/files/etpc/2006v5n1nar1.pdf. 